\title{
Cronologia Visorama
}

Cronologia Visorama, item e Agora-Capacete organizada por Ricardo Basbaum. Algumas informações foram acrescentadas por Analu Cunha especificamente para este dossiê da revista Concinnitas.

1988

agosto: Ricardo Basbaum organiza um grupo de estudos semanal de arte contemporânea. Brígida Baltar, Eduardo Coimbra e João Modé juntam-se ao grupo. As reuniões contam também com a participação dos artistas Carla Guagliardi, Márcia Ramos, Rosângela Rennó, Valeska Soares, Marcus André, Rodrigo Cardoso, Analu Cunha, Alex Hamburger, Márcia X., Franklin Cassaro, Maria Moreira, Claudia Bakker [Doctors],_Marcos Chaves, Fernanda Gomes, Enrica Bernardelli, Jorge Barrão, Ricardo Mauricio, Alexandre Dacosta, dentre outros. Ainda sem nome, o grupo se autodenomina GEAMOCO - Grupo de Estudos de Arte Moderna e Contemporânea.

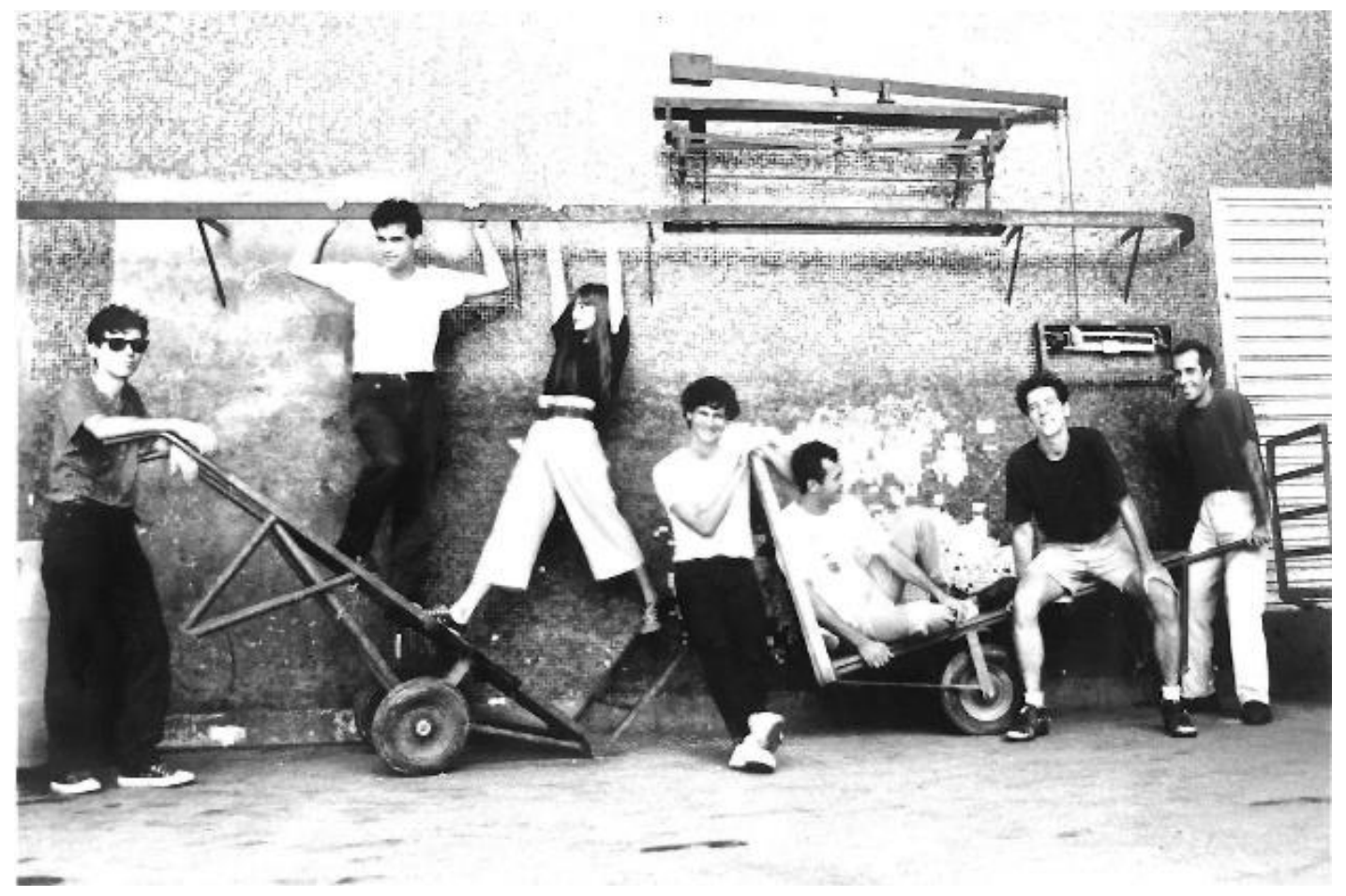

Ricardo Cunha

Foto de divulgação da exposição Sete no Grandjean de Montigny, 1989

Da esquerda para a direita: André Costa, Rodrigo Cardoso, Analu Cunha, Ricardo Mauricio, Marcos Chaves, João Modé e Ricardo Becker 
abril: Possível Imagem, exposição no Solar Grandjean de Montigny, PUC-RJ, com Brígida Baltar, Carla Guagliardi, Eduardo Coimbra, Márcia Ramos, Ricardo Basbaum e Valeska Soares. O texto de apresentação de "Possível imagem" é de Hermano Vianna. Foi realizado um debate, com participação do crítico Paulo Sergio Duarte. O projeto desta exposição recebeu o Prêmio FIAT de Artes Plásticas. No ano anterior, os artistas André Costa, Analu Cunha, João Modé, Marcos Chaves, Ricardo Becker, Ricardo Maurício e Rodrigo Cardoso inauguraram o espaço expositivo em arte contemporânea do Grandjean de Montigny com a exposição Sete.

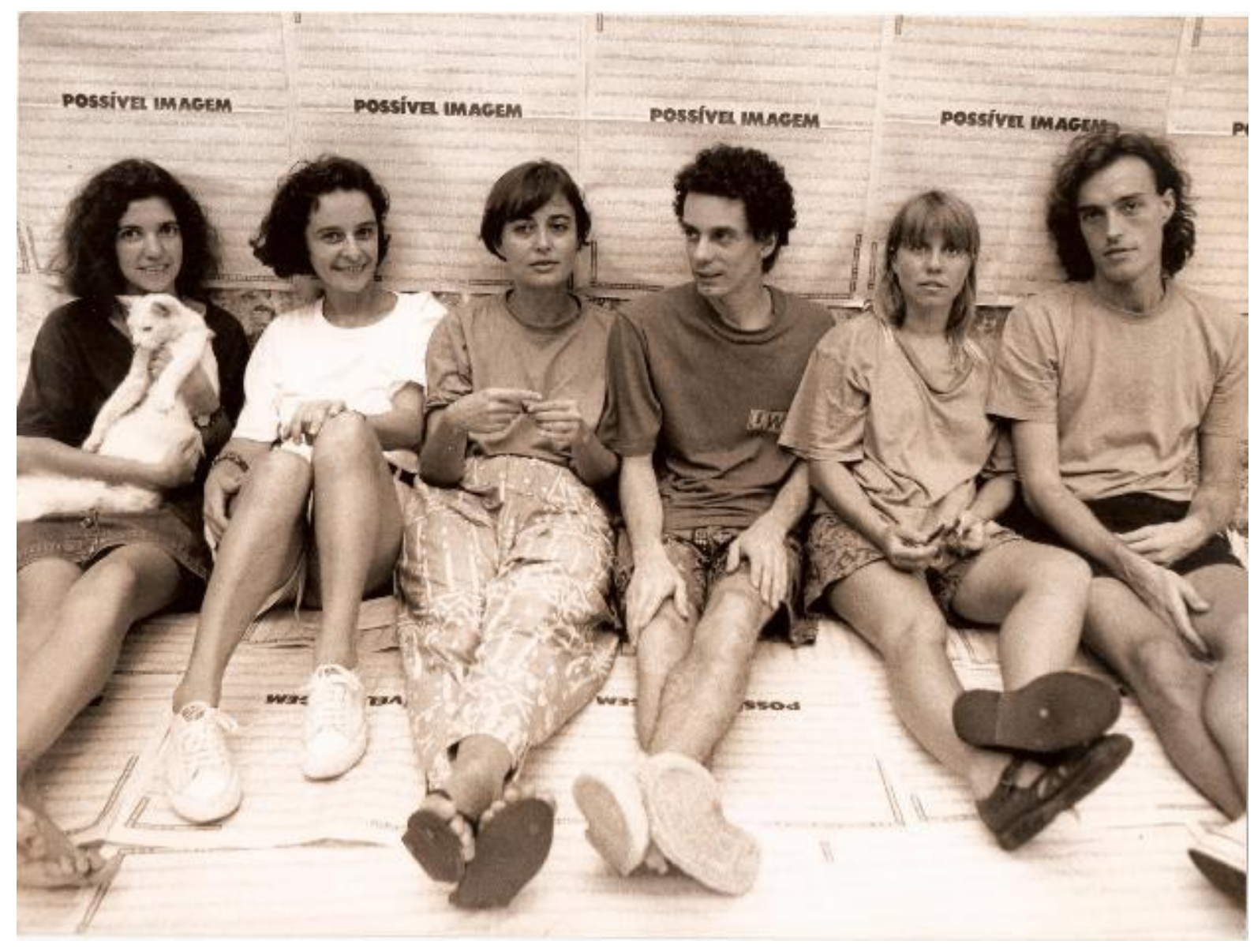

Rodrigo Cardoso

Foto de divulgação da exposição Possível imagem no Grandjean de Montigny, 1990

Da esquerda para a direita: Marcia Ramos, Carla Guagliardi, Valeska Soares, Ricardo Basbaum, Brigida Baltar, Eduardo Coimbra 
1991

junho: O grupo de estudo passa a se denominar Visorama.

outubro: O Visorama organiza um ciclo de discussões sobre arte contemporânea, na Escola de Artes Visuais do Parque Lage. São sete encontros, todos os sábados, com projeções de slides seguidas de debates. Inicia-se a organização de um banco de imagens que, três anos depois, chega a reunir mais de 2000 slides. O ciclo Visorama ${ }^{1}$ foi organizado e produzido por Carla Guagliardi, Eduardo Coimbra, João Modé, Márcia Ramos, Marcus André, Ricardo Basbaum, Rodrigo Cardoso, Rosângela Rennó e Valeska Soares.

\section{2}

março: Eduardo Coimbra e Ricardo Basbaum escrevem o texto Tornando Visível a Arte Contemporânea ${ }^{2}$, em resposta a uma série de artigos de Ferreira Gullar publicados pelo caderno Idéias, do Jornal do Brasil. O editor do caderno, Wilson Coutinho, recusa-se a publicar o artigo, que permanece inédito até 1995.

abril: Visorama organiza o seminário Visorama na $U F R J^{3}$, no Fórum de Ciência e Cultura da Universidade Federal do Rio de Janeiro, com a participação dos artistas Milton Machado e Tunga, dos críticos e curadores Ligia Canongia e Paulo Venâncio Filho, dos pesquisadores e professores Silvia Pimenta, Eduardo Jardim e Janice Caiafa e do psicanalista Aluisio Menezes. O cartaz do seminário é de autoria de Brigida Baltar.

junho-agosto: o grupo Visorama realiza diversas entrevistas e encontros com artistas em passagem pelo Rio de Janeiro, como Michelangelo Pistoletto, Alfredo Jaar, Anthony Gormley, Bill Woodrow e Mark Dion.

\footnotetext{
${ }^{1}$ A programação completa do Ciclo Visorama está incluída neste dossiê.

${ }^{2}$ COIMBRA, Eduardo e BASBAUM Ricardo. Tornando visível a arte contemporânea in: Arte Contemporânea Brasileira. Rio de Janeiro: Marca D'Água, 2001

${ }^{3}$ A programação completa do Visorama na UFRJ está incluída neste dossiê.
} 


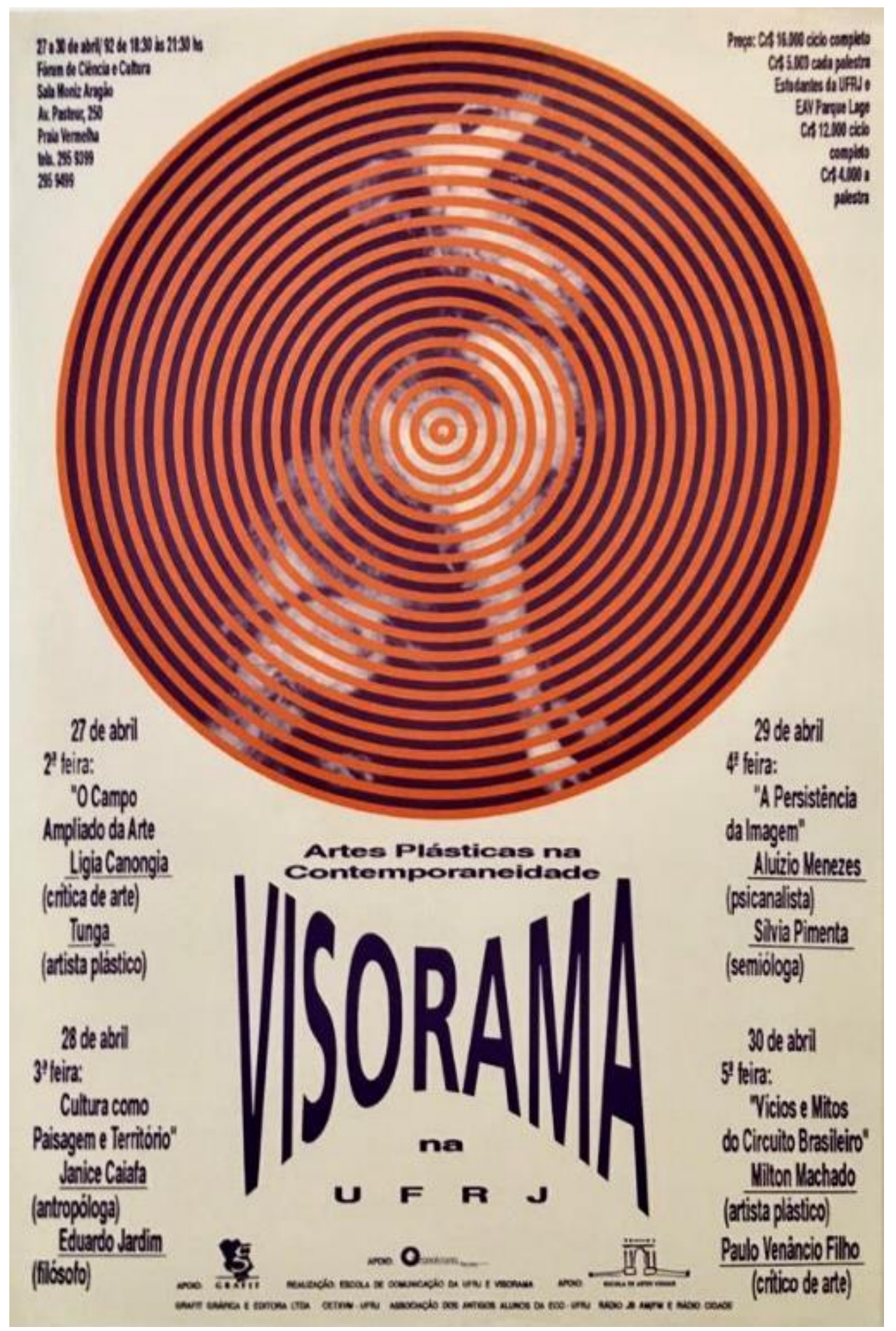

Brígida Baltar

Cartaz Visorama na UFRJ, 1992 

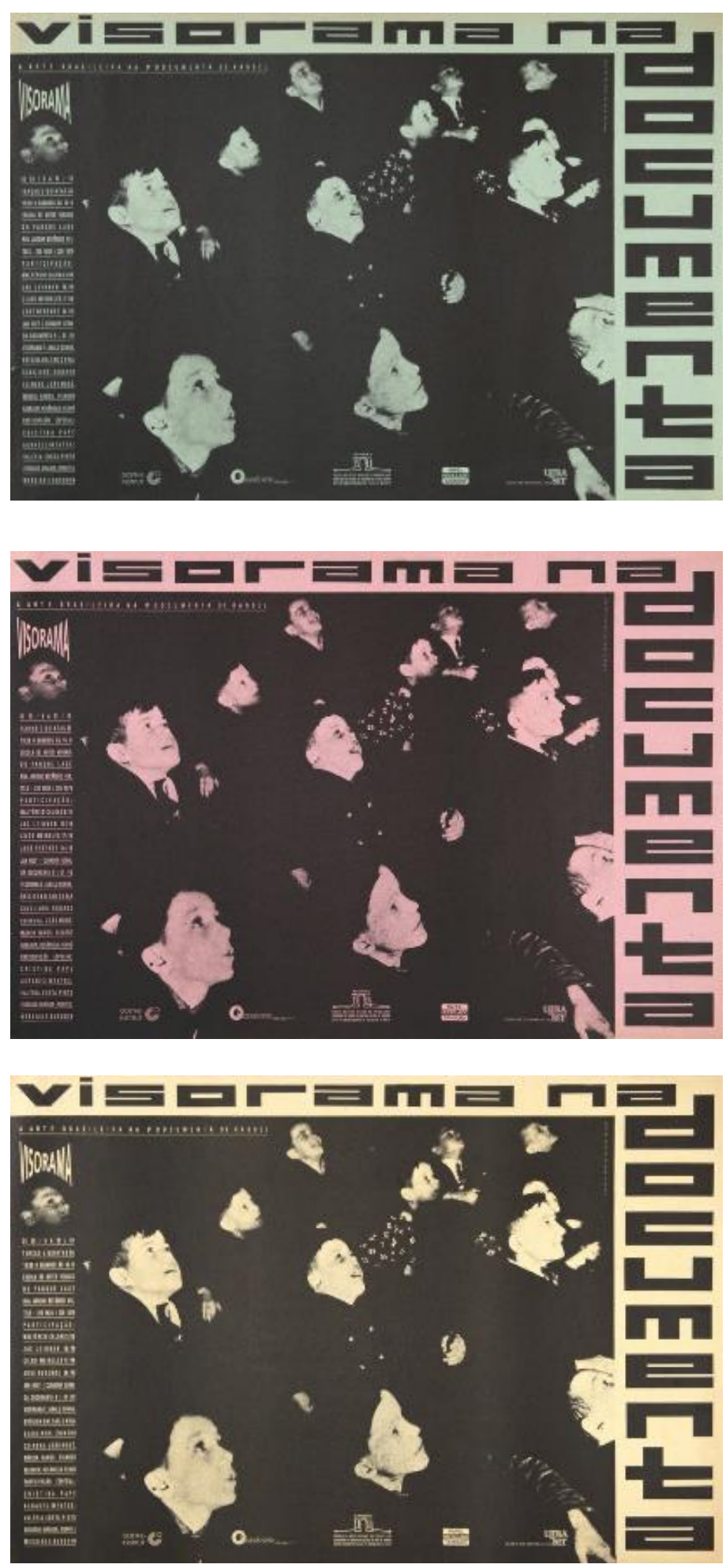

Brígida Baltar

Cartaz Visorama na Documenta, 1992

Foto Wilton Montenegro 
setembro: O Visorama organiza, na Escola de Artes Visuais do Parque Lage, o ciclo de debates Visorama na Documenta, com a participação dos artistas Cildo Meireles, Jac Leirner, José Resende e Waltércio Caldas. O evento teve duração de cinco semanas e contou no seu encerramento com palestra de Jan Hoet, curador geral da IX Documenta. O cartaz e o folder do evento são de autoria de Brigida Baltar.
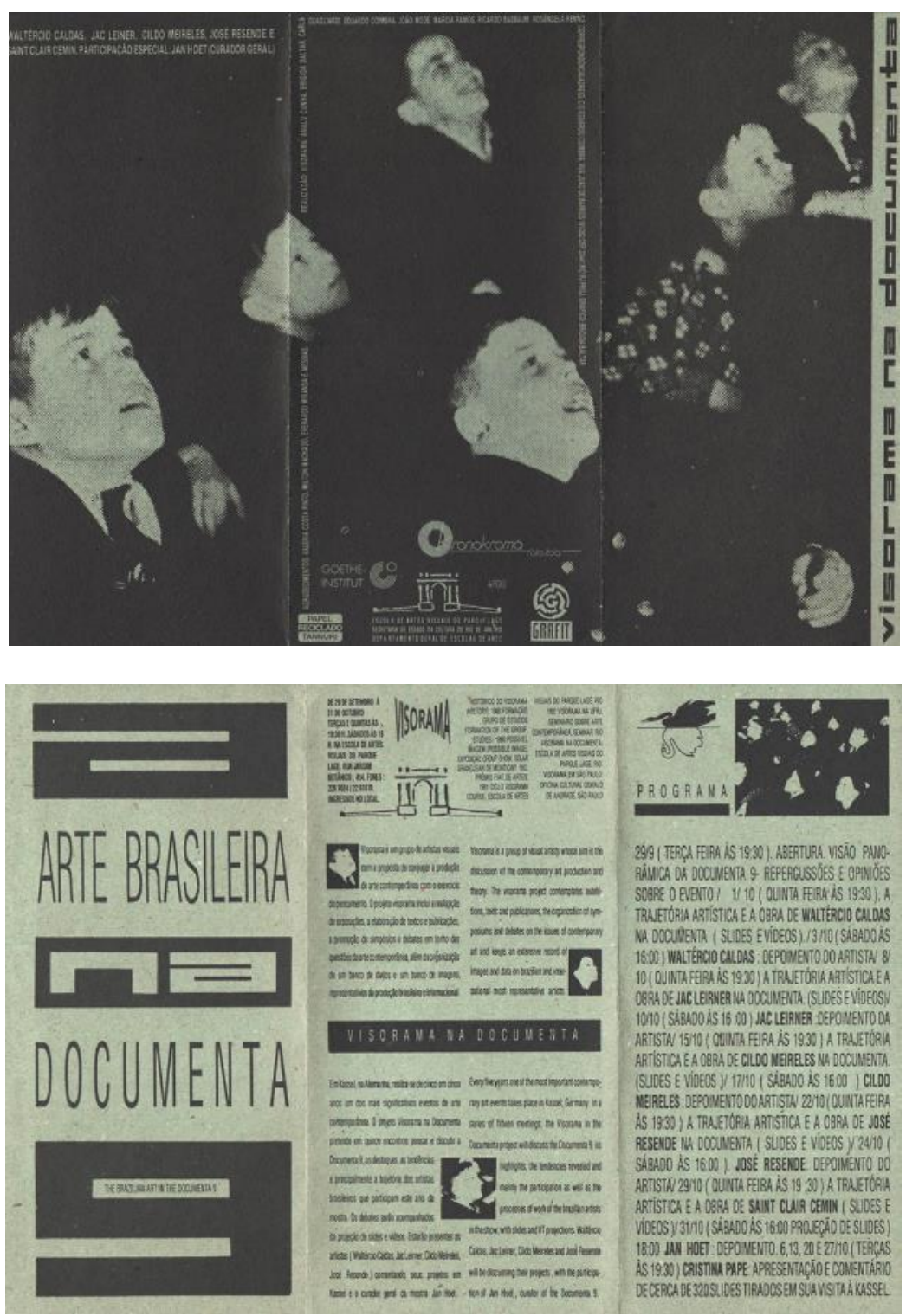

Brígida Baltar

Frente e verso folder Visorama na Documenta, 1992

http://acervo.memorialage.com.br/xmlui/bitstream/handle/123456789/12359/JCG-0908.pdf 
outubro: Visorama se encontra com a artista norte-americana Barbara Kruger, que assiste a uma projeção de slides e conversa com os artistas do grupo. Depois de um passeio de carro pela cidade, todos almoçam no restaurante Look, no Leblon. A artista Analu Cunha guarda os guardanapos utilizados no almoço e realiza o trabalho Look, 26 de outubro de 1992, 1993.

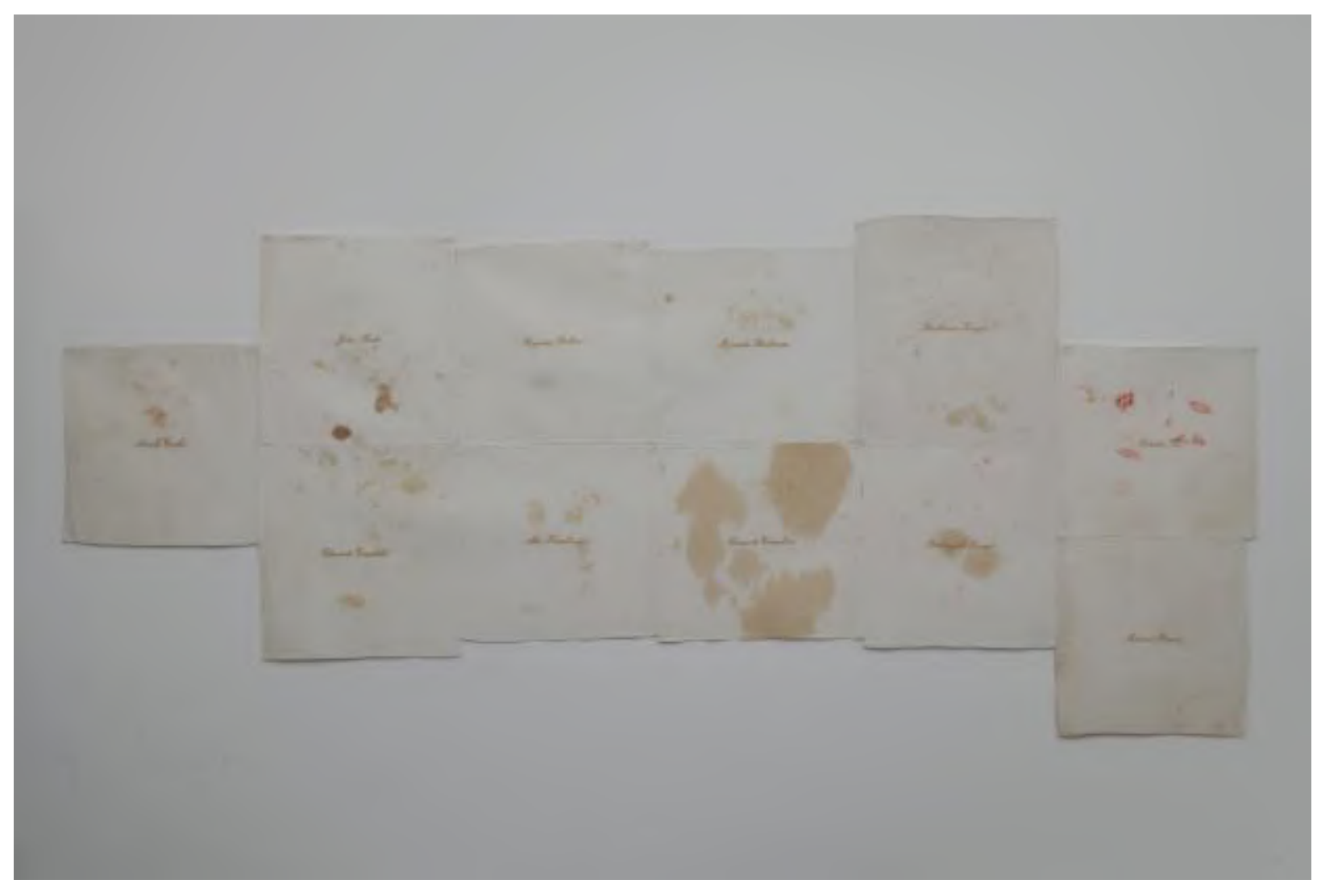

Analu Cunha

Look, 26 de outubro de 1992, $1993^{4}$

Fio de ouro bordado sobre guardanapo de tecido $100 \times 250 \mathrm{~cm}$

Foto Wilton Montenegro

\footnotetext{
${ }^{4} \mathrm{O}$ trabalho reproduz, a partir dos guardanapos utilizados, a disposição da mesa do almoço no restaurante, hoje inexistente, Look, no Leblon, em torno da artista Barbara Kruger: da esquerda para a direita: Analu Cunha (cabeceira); parte de cima: João Modé, Brígida Baltar, Ricardo Basbaum, Barbara Kruger, Marcia X. e Marcia Ramos (cabeceira). E, em baixo, da direita para a esquerda: Rosângela Rennó, Eduardo Coimbra, Alex Hamburger, Eduardo Candelot. Imagem na cronologia.
} 
dezembro: o Visorama realiza em São Paulo o ciclo de debates Visorama na Oswald (quatro conferências sobre arte contemporânea), na Oficina Cultural Oswald de Andrade.

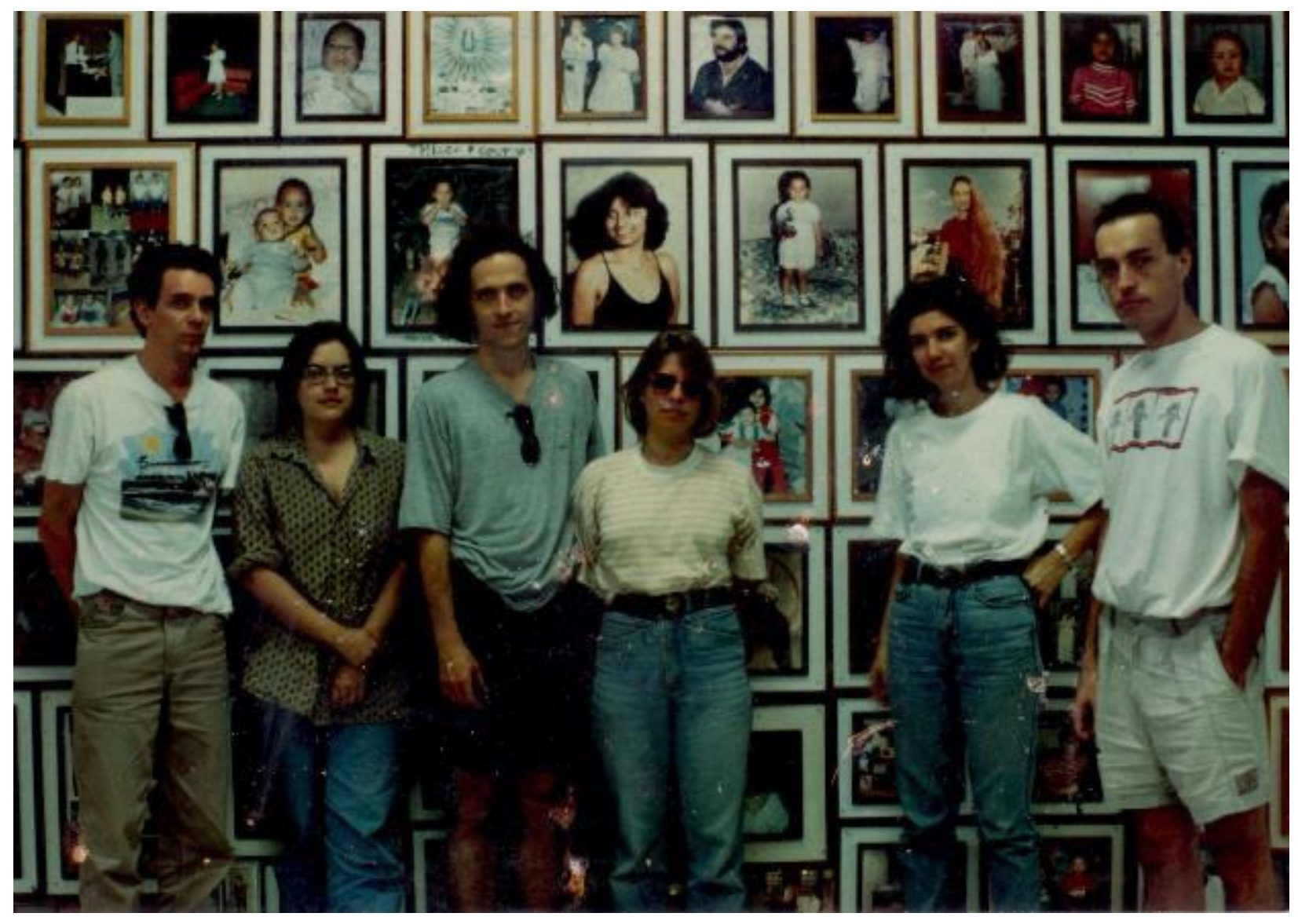

Fotógrafo desconhecido

Visorama a caminho de São Paulo, 1992/1993

Ricardo Basbaum, Rosângela Rennó, João Modé, Brígida Baltar, Marcia Ramos e Eduardo Coimbra Acervo Brígida Baltar

\section{3}

agosto: O Visorama organiza, na Escola de Artes Visuais do Parque Lage, a discussão Visorama em Veneza, com a participação de Rosângela Rennó, Angelo Venosa, Márcio Doctors, Alex Hamburger e Lygia Pape, tendo como tema a XLV Bienal de Veneza, a mostra Apperto 93 e a exposição Brasil: Segni d'Arti, Libri i Video 1950-1993. 
1994

agosto: Visorama é convidado a participar do III Fórum Brasília de Artes Visuais, onde realiza um trabalho coletivo a partir do tema proposto Cidade Imaginada. O projeto é publicado no catálogo do evento.

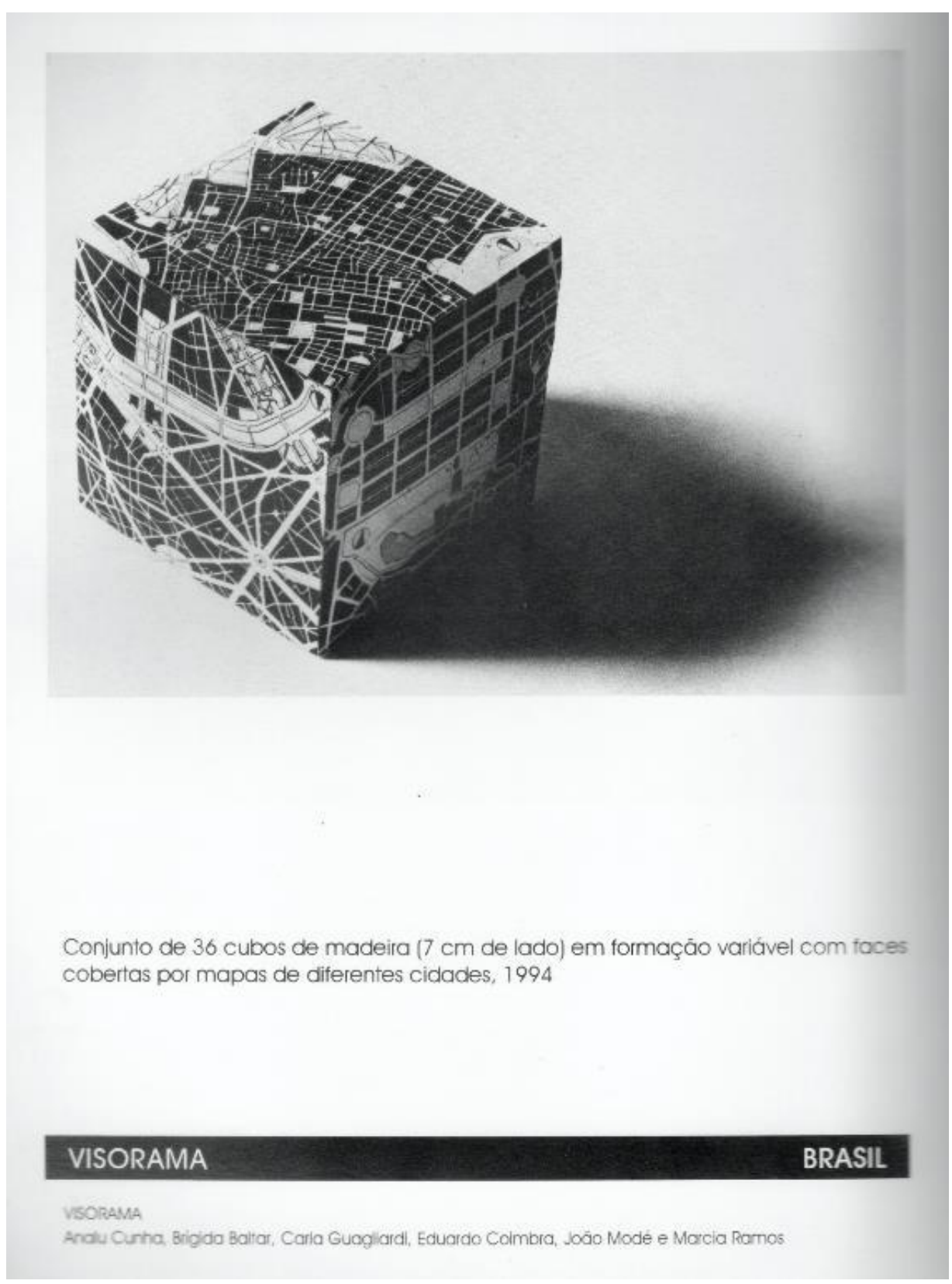

Página do catálogo Exposição Cidade imaginária

Curadoria de Evandro Salles

Fundação Athos Bulcão, Brasília DF, 1994 


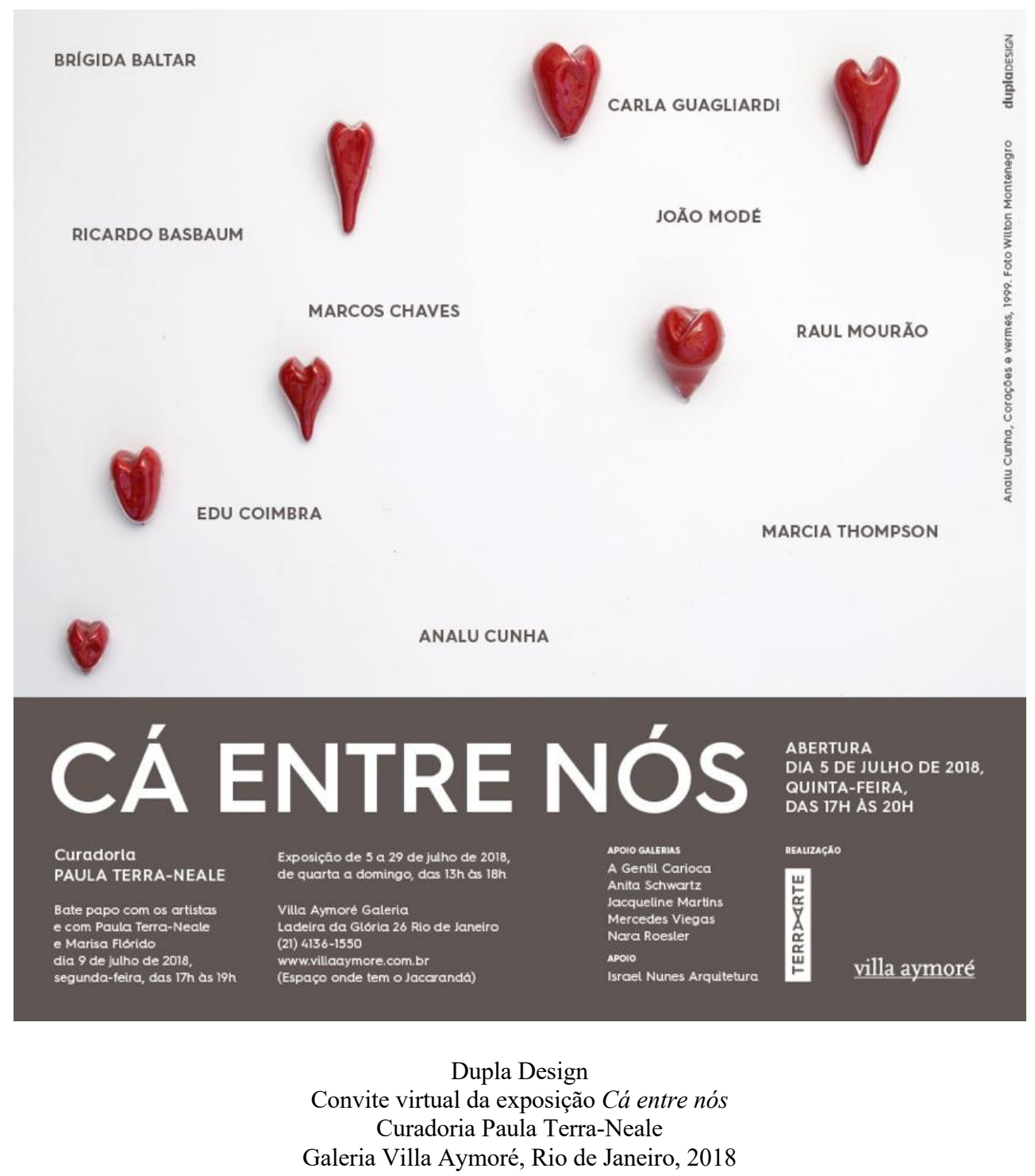

\section{8}

julho: a curadora Paula Terra-Neale reúne, na exposição Cá entre nós (Galeria Villa Aymoré, Rio de Janeiro), os artistas do Visorama Analu Cunha, Brígida Baltar, Carla Guagliardi, Edu Coimbra, João Modé e Ricardo Basbaum e aqueles que, ainda que não fossem atuantes no grupo, faziam parte da mesma rede de amigos: Marcia Thompson, Marcos Chaves e Raul Mourão. Na ocasião, Paula Terra-Neale anunciava:

Os artistas de Cá entre nós trabalham e se relacionam como amigos desde os anos 80-90, quando ainda bem jovens e aprendiam sobre a produção contemporânea 
de arte por meio de revistas estrangeiras em que fotografavam e faziam grupos de estudos analisando os slides trazidos por todos para as reuniões formais e casuais, numa atuação que durou de uns 3 a 4 anos. Eles todos não só são produtores de artes, mas também de conhecimento sobre arte, atuando como artistas pesquisadores, professores, editores de revistas, criadores de espaços, mostras, eventos, atuando como veículos de fomentação da arte contemporânea brasileira no Rio, no Brasil e no mundo.

Cá entre nós é isso - uma mostra que tem esse caráter de pesquisa curatorial experimental que tem fundamentos históricos muito sólidos mas também uma pulsão de vida forte; que homenageia esse campo da produção de arte que se faz permeada por laços e afetos, por trocas existenciais ricas de sentido.

As situações vividas na arte, na arte no Rio, na arte contemporânea, muitas vezes com muita precariedade de meios e recursos faz surgir em oposição uma arte potente, poderosa, impregnada de um sentido crítico, e de proposições: experimentais, sensoriais e intelectuais que sobrepujam assim a todos os limites que a realidade nos impõe. Mas que também quer mudar essa condição limitadora. 


\section{Cronologia item / AGORA e AGORA/Capacete}

Em 1995, Eduardo Coimbra, Raul Mourão e Ricardo Basbaum lançam o primeiro número da revista item-1 - textos de artistas com festa na Escola de Artes Visuais do Parque Lage. No mesmo ano, é lançada item-2 - música no Paço Imperial, na Livraria Cultura em São Paulo, no Espaço Cultural 508 Sul, em Brasília, e no Massimo Bar Ristorante, em Goiânia. João Modé assume o projeto gráfico da revista.

No início de 1996, é realizado encontro com Nicholas Logsdail, da Lisson Gallery, Londres, que é apresentado à revista item e ao projeto Visorama. Em março, é lançada a revista item-3 tecnologia, com projeto gráfico de João Modé, no MAM/Rio, e na Galeria Camargo Villaça, em São Paulo. O Visorama participa do evento Arte Contemporânea: contribuições canadenses, no Paço das Artes, em São Paulo. No mesmo ano, a revista é lançada em Belo Horizonte, no Centro Cultural da UFMG e em Porto Alegre, no Centro Municipal de Cultura. Em novembro, é lançada item-4 - sexualidade, no Espaço Cultural Sergio Porto, no Rio de Janeiro e, no mês seguinte, no Solar do Unhão, Salvador.

Em 1998, Helmut Batista cria o Espaço P, no apartamento 904 da Rua Paissandu 93, Flamengo, Rio de Janeiro, com as exposições individuais de Ana Infante e Ricardo Basbaum. No mesmo ano, O Espaço P realiza as exposições de Andrea Fraser e Marcel Dzama.

Espaço Purplex (ex-Espaço P) é criado em 1999, e apresenta a instalação White Cue de Rubens Mano, no sub-solo desocupado de um restaurante, em Santa Teresa. Em agosto, Eduardo Coimbra, Raul Mourão e Ricardo Basbaum criam o AGORA - Agência de Organismos Artísticos, que apresenta em seu primeiro evento as exposições de Laura Lima e Raul Mourão, na Fundição Progresso. No mesmo ano, Capacete Entretenimentos (ex-Espaço Purplex) realiza os projetos individuais de Marssares, no Aterro do Flamengo, Tiago Carneiro da Cunha, na Fundição Progresso e do artista francês Bruno Serralongue, que trabalhou por um mês como fotógrafo do Jornal do Brasil. A convite do AGORA, o artista, editor e escritor norte-americano Jordan Crandall realiza palestras no Centro de Arte Hélio Oiticica, na Escola de Artes Visuais do Parque Lage e na Escola de Comunicações e Artes da USP, e São Paulo. A revista item participa do I Seminário Internacional de Revistas de Arte, na Cidade do México. AGORA e Capacete Entretenimentos lançam seu programa de captação de associados, como forma de viabilizar apoio 
a estas iniciativas. Na ocasião é apresentado o vídeo G. $x$ eu, de Raquel Couto, realizado a partir do trabalho homônimo de Ricardo Basbaum.

No ano 2000, o AGORA realiza o evento Cinema Experimental de artista: 3 filmes de Karin Schneider e Nicolás Guagnini, em parceria com o Espaço Unibanco de Cinema. Após a apresentação, foi realizada palestra com o pesquisador Luiz Cláudio da Costa ${ }^{5}$, seguida de debate com a presença dos realizadores. Em parceria com o MAC/Niterói, o AGORA promove a palestra do artista catalão Antoni Muntadas. Para celebrar a inauguração do Espaço AGORA/Capacete, na Rua Joaquim Silva 71, Lapa, em maio, AGORA e Capacete Entretenimentos convidam o grupo multimídia Chelpa Ferro, que apresenta a performance $A$ garagem do gabinete de Chico. AGORA assina contrato com o site super11.net para a realização de uma coluna semanal de arte contemporânea. A cada semana é apresentado um texto inédito, escrito por um dos membros do AGORA, uma entrevista com um personagem de destaque do circuito de arte contemporânea e dois comentários críticos sobre trabalhos de artistas brasileiros e internacionais. A coluna fica no ar por três meses. Tatiana Grinberg inaugura, em agosto, a nova sede do AGORA. Na mesma época, a agência realiza um debate, no MAM/Rio, sobre as exposições de Eduardo Coimbra, Carlos Bevilacqua e Ricardo Basbaum, em cartaz naquela instituição. Além dos artistas, o debate contou com a participação da crítica de arte, curadora e pesquisadora Glória Ferreira. Capacete Entretenimentos apresenta novos trabalhos dos artistas Ricardo Basbaum e Marssares, no Espaço AGORA/Capacete e nos jardins de uma casa em Santa Teresa. Na inauguração, é lançado o samba Sinal Nave Samba, de Luiza Maria. Capacete Entretenimentos realiza exposição e evento com trabalhos em vídeo e instalações de Dominique Gonzalez-Foerster e Pierre Huyghe, no Espaço AGORA/Capacete, na Casa França-Brasil e nos jardins de uma casa em Santa Teresa, em novembro. No mesmo mês, O AGORA promove a projeção do filme de Andy Warhol Haircut 1 (1963), seguida de palestra de Roy Grundman da Boston University, apresentada por Luiz Claudio da Costa. No final do ano, a artista Livia Flores apresentou, no Espaço AGORA/Capacete, exposição individual com filmes Super-8 projetados nas paredes da galeria. É realizado um debate, com a participação de Paulo Herkenhoff e Ricardo Basbaum.

\footnotetext{
${ }^{5}$ Hoje professor do IART/UERJ e do PPGArtes/UERJ.
} 
No início de 2001, Capacete Entretenimentos apresenta trabalhos de Hans-Christian Dany e Ducha no Espaço AGORA/Capacete. Em seguida, abre a exposição individual de Fernanda Gomes. Na ocasião, foi realizado um debate, com participação de Paulo Venâncio Filho e Raul Mourão. Capacete Entretenimentos realiza evento com trabalhos dos artistas japoneses Miyuki Kawamura, Nobuyoshi Araki e Tsuzuki Kyocihi e curadoria de Fumio Nanjo e Nobuo Nakamura, no meio do ano. O Espaço AGORA/Capacete é selecionado pelo programa Petrobrás Artes Visuais: o projeto patrocinado inclui a realização de seis exposições, a publicação de dois números da revista item e a construção de um website, lançado no mês seguinte. Em setembro, O AGORA apresenta a exposição Neblina, orvalho, maresia: Coletas, de Brígida Baltar, com lançamento do livro da artista. É realizado um debate, com participação de Ligia Canongia e Eduardo Coimbra. No mesmo ano, O AGORA realiza a exposição Outra Coisa no Museu Vale do Rio Doce (Vila Velha, ES), reunindo os trabalhos dos artistas cariocas Brígida Baltar, João Modé, Eduardo Coimbra, Ricardo Basbaum e Raul Mourão. Na ocasião, foi montada uma sala dedicada ao Visorama. Paralelamente, Capacete Entretenimentos apresenta trabalhos de Uri Tzaig, Joachim Koerster e Matthew Buckimgham na galeria, em outubro. No mês seguinte, O AGORA apresenta performance OURO PARA TODOS / GOLD FOR EVERY BODY, do grupo Foreign Investiment. No final do ano, Capacete Entretenimentos realiza exposição com trabalhos do artista Tiago Carneiro da Cunha em parceria com o artista italiano Enrico David.

Em 2002, AGORA e Capacete Entretenimentos desfazem sua parceria, seguindo, a partir desta data, como agências independentes. O site do AGORA é atualizado, com novo domínio. É lançada a revista item-5 - afro-américas no AGORA e no MAM/São Paulo. O AGORA apresenta a exposição Heatseeking do artista norte-americano Jordan Crandall. Em março, O AGORA realiza a exposição Love's House, no hotel Love's House (Lapa, RJ), reunindo trabalhos de treze artistas cariocas - Brígida Baltar, Carla Guagliardi, Ricardo Becker, Eduardo Coimbra, Fernanda Gomes, Ricardo Basbaum, Tatiana Grinberg, João Modé, Raul Mourão, Lívia Flores, Marcos Chaves, Chelpa Ferro e Laura Lima. Em maio, O AGORA apresenta AGORA AGORA / AGORA RIO DE JANEIRO, um conjunto de 30 filmes e vídeos (realizados em Super-8 e U-Matic entre 1979 e 1982) na primeira exposição individual de Paulo Bruscky na cidade. Na ocasião, foi realizado um 
debate, com a presença do artista e do crítico de arte e poeta Adolfo Montejo Navas. Durante um final de semana de junho, é exibido o vídeo $3 \times 0$, do artista e terapeuta Lula Wanderlei. No mês seguinte, O AGORA apresenta a exposição Estímulo Puro de João Modé. Foi realizado um debate com o artista, em que as cadeiras foram distribuídas livremente pela galeria, de modo a integrar o artista e o público aos trabalhos expostos. Com o patrocínio da Prefeitura do Rio, através da Secretaria das Culturas e do RIOARTE, a Casa da Palavra, o Canal Contemporâneo e o AGORA lançam o livro Love's House. O livro é lançado no Rio e São Paulo.

No espaço AGORA são realizadas, em 2003, as primeiras reuniões do grupo artesvisuais_políticas, que organizou eventos de resistência dos artistas frente ao acordo negociado pela Prefeitura do Rio de Janeiro com a Fundação Guggenheim. No mesmo ano, é lançada a revista item-6 - fronteiras (que contou com a colaboracão de artistas e pensadores brasileiros, portugueses e norte-americanos) durante a festa de encerramento do evento Grande Orlândia, no Rio de Janeiro. A revista também é lançada no Centro Universitário Maria Antonia - USP em São Paulo. Na ocasião, foi realizado debate que reuniu os editores da item e de outras revistas e publicações dedicadas à arte e à cultura contemporânea.

Em setembro de 2003, O AGORA encerra suas atividades. 